\title{
Evolução da margem de comercialização da erva mate no Rio Grande do Sul
}

Evolution of commercialization of the Ilex paraguariensis in Rio Grande do Sul

\author{
Vanclei Zanin ${ }^{1}$; Leandro Garcia Meyer²*
}

${ }^{1}$ Fundação de Economia e Estatística do Rio Grande do Sul (FEE-RS) - Pesquisador - Rua Duque de Caxias, 1691 - Centro - 13418-445 - Porto Alegre, RS - Brasil. ${ }^{2}$ Universidade Estadual do Norte do Paraná (UENP) - Professor - PR-160, 817, 86300-000, Cornélio Procópio, PR - Brasil <leandro.meyer@gmail.com>

\section{Resumo}

A erva-mate é um produto fortemente enraizado à cultura, à história e à tradição de parcelas importantes da população brasileira, sobretudo na região Sul. A partir dos anos 1990 o setor passou por modificações, como a desregulamentação e o aumento da competição externa. Nesse contexto, esse trabalho teve por objetivo investigar a evolução da margem de comercialização da erva-mate no mercado gaúcho, grande produtor e principal consumidor nacional, no período janeiro de 1998 a dezembro de 2016. Investigou-se também o comportamento da produção, do consumo e do comércio externo. Os resultados indicaram aumento da produção cultivada, reflexo da desregulamentação, enquanto que o comércio externo teve importância marginal no total de vendas, tanto antes quanto após a desregulamentação. Os resultados indicaram também substancial estabilidade da margem, e os preços só foram alterados consideravelmente por um choque de oferta em 2013. Por se tratar de uma cultura permanente, cuja oferta é inelástica aos preços, pode-se levar tempo para retornar ao nível anterior. Por fim, destaca-se a importância de diversificar o consumo e da organização de informações setoriais como ferramentas para desenvolver o setor e as economias locais a ele vinculadas.

Palavras-chave: consumo, Ilex paraguariensis, produção, mercado agrícola

\begin{abstract}
Ilex paraguariensis is a very traditional herb consumed by a large share of Brazilian citizens, mainly in the south region, where it is related to local culture and history. Its market passed through several changes from the 1990's until the present, such as deregulation and an increasing international competition. Considering this scenario, this research studied this product gross margin between January 1998 and December 2016 in the state of Rio Grande do Sul—which is this herb main supplier and consumer. Production, consumption and international trade patterns were also analyzed. Results show that cultivated production increased after deregulation, meanwhile international trade was responsible for a small share of total sales, both before and after deregulation. Results also show great stability for gross margin, and prices changed significantly only as consequence of a supply shock in 2013. Since it is a perennial plant - and therefore its supply is relatively inelastic - it will probably take some years until prices return to previous levels. To conclude, it is important to state the need to spread consume through other regions of Brazil and to organize sectorial data in order develop this sector and local economy related to it.
\end{abstract}

Keywords: consumption, Ilex paraguariensis, production, agricultural market

\section{Introdução}

A importância da erva-mate, Ilex paraguariensis Saint Hillaire, para os estados do sul brasileiro, bem como aos países vizinhos (Argentina, Uruguai e Paraguai) é histórica. Produto com grande relevância política, econômica e social, consumido inicialmente somente pelos povos originários, sobretudo pelos Guaranis, foi assimilado pelos colonizadores europeus e amplamente explorado pela Companhia de Jesus em suas reduções jesuíticas ainda no período colonial da região (Embrapa, 2010). Sua expressão como produto de exportação na época colonial e mesmo no século XIX não pode ser negligenciada, sendo, um dos responsáveis pela própria emancipação do Paraná em relação à quinta comarca de São Paulo. No caso do Rio Grande do Sul, o valor cultural da erva-mate, com mais de quatrocentos anos de história, é tamanho que a construção do símbolo do gaúcho típico conta com o chimarrão como sua "bebida símbolo" e com leis que assim o designam (Rio Grande do Sul, 2003).

Notadamente, a erva-mate é um produto fortemente enraizado à cultura, à história e à tradição da região que congrega os estados do sul do Brasil e de países vizinhos como: a Argentina, o Uruguai e o Paraguai. Não por acaso que, com exceção do Uruguai, estes são os principais produtores da erva-mate no mundo. De acordo com dados da Organização das Nações Unidas para a Alimentação e a Agricultura (FAO, 2017) para a média

Recebido: 04 ago. 2018

Aprovado: 20 jan. 2018 
do período 2010-2014, a produção de erva-mate oriunda de plantio foi de 573 mil toneladas no Brasil, seguido de 243 mil toneladas na Argentina e de 80 mil toneladas no Paraguai.

A partir dos anos 1990, o setor ervateiro brasileiro sofreu significativas alterações. A criação do Mercado Comum do Sul [MERCOSUL] e a consequente liberalização do comércio entre os países signatários suscitou diversos trabalhos que examinaram o impacto do livre comércio sobre o setor nacional. Efetivamente, as importações brasileiras a partir de 1995, fomentadas pela liberalização advinda do Mercosul e também pela criação do Plano Real - com a manutenção da taxa de câmbio sobrevalorizada - atingiram seu auge, valor em torno de US\$ 10 milhões ao ano, de produto originário, majoritariamente, da Argentina (Oliveira e Waquil, 2015).

A partir de 1999, com a mudança do regime de câmbio para flutuante, as importações recuam e passam a girar em torno de US\$ 2 a 3 milhões nno $^{-1}$ depois dos anos 2000 (MDIC, 2017), com alguma elevação em anos de menor safra interna. Assim sendo, mesmo com a liberalização comercial que se seguiu a criação do Mercosul, a erva-mate continua sendo um produto voltado ao consumo interno, com baixa proporção de produto externo no total ofertado. A única exceção é o Uruguai que por não produzir internamente acaba comprando todo o produto consumido, principalmente do Brasil.

Em termos de exportações, desde 1990, o saldo foi amplamente positivo. As vendas externas giraram em torno de US\$ 35 milhões ano ${ }^{-1}$ na década de 1990, passando a girar entre US\$30 a 40 milhões até 2010, quando o valor cresceu, devido sobretudo a alta dos preços, para algo em torno de US\$ 80 milhões ao ano (MDIC, 2017). Em relação aos destinos, dados de valor exportado do último quinquênio (2012-2016) indicaram: Uruguai (85\%); Chile (4,8\%); Estados Unidos (2,7\%) e Alemanha (2,5\%) como principais mercados da erva-mate brasileira. Nooua-se, portanto, crescimento do saldo, favorável da balança comercial do setor, nos últimos anos, cujo foco foi o mercado uruguaio.

Outra mudança considerável no setor ervateiro, conforme ressalta Valduga et al. (2003), foi a sua desregulamentação. A atividade ervateira até o início da década de 1990 era regulamentada por leis que determinavam desde a padronização do produto até as épocas de colheita. A partir de 1992, o estado deixou de impor essas regras ao setor que passa a vivenciar um ambiente mais competitivo, o que favoreceu o aumento da área plantada.

Ressalta-se que a produção de erva-mate convive com dois sistemas produtivos. A produção extrativa, $35 \%$ do total nacional entre 2012-2015, oriunda de ervais nativos, que se concentrou, sobretudo, no Paraná, produção média de 257 mil toneladas, entre 2012-2015, ou $84 \%$ da produção extrativa nacional (IBGE, 2017a).
A produção cultivada, 65\% do total nacional entre 20122015, em áreas de ervais plantados, nessa produção o Rio Grande do Sul foi o principal produtor nacional, com produção média de 273 mil toneladas entre 2012-2015, ou 49\% da produção cultivada nacional (IBGE, 2017b). Soma-se a coexistência entre produção extrativa e cultivada o fato de se tratar de uma cultura permanente, que leva de 4 a 7 anos para que um erval plantado entre em produção plena (Valduga et al., 2003), e tem-se um cenário bastante complexo para os diferentes elos da cadeia ervateira.

Nesse contexto de desregulamentação e aumento da competição externa a compreensão da evolução dos preços, tanto ao produtor quanto ao varejo é fundamental aos agentes envolvidos nesse setor. Adicionalmente, por se tratar de uma cultura permanente, que depende da expectativa de rentabilidade no longo prazo, o entendimento da distribuição da renda gerada no setor é primordial para se analisar a dinâmica setorial.

Assim sendo, o trabalho teve por objetivo investigar a evolução da margem de comercialização da erva-mate no mercado gaúcho, analisando também seus dois componentes - o preço ao varejo e ao produtor. Pretendeu-se ainda apresentar um panorama da produção, comércio externo e do consumo de erva-mate no período recente.

\section{Material e Métodos}

Em economias modernas a produção e o consumo estão separados no tempo e no espaço. Assim, faz-se necessário um conjunto de atividades - transporte, armazenagem, beneficiamento - para que o consumidor final tenha acesso ao produto apto ao consumo (Barros, 2007). É a comercialização agrícola que engloba esse conjunto de atividades que tem por objetivo a transferência bens e serviços do produtor ao consumidor final.

Dentro deste arcabouço foi que surge o interesse pelo estudo da margem de comercialização - preço do serviço de comercialização. Barros (2007) mostrou que a margem é dada pela diferença entre o preço pelo qual um intermediário (ou um conjunto de intermediários) vende uma unidade de produto e o pagamento que se faz pela quantidade equivalente que precisa comprar para vender essa unidade. Algebricamente tem-se eq. (1):

$$
\mathrm{MT}=\mathrm{P}_{\mathrm{v}-} \mathrm{P}_{\mathrm{p}}
$$

onde, MT: margem absoluta total, Pv: Preço ao varejo e Pp: preço ao produtor, em quantidades equivalentes.

A margem também pode ser expressa de forma relativa (MTr) ao preço final, conforme eq. (2).

$$
\operatorname{MTr}=\left(\mathrm{P}_{\mathrm{v}-} \mathrm{P}_{\mathrm{p}}\right) / \mathrm{P}_{\mathrm{v}}
$$

Fazendo uso desses conceitos o trabalho buscou analisar a evolução da margem de comercialização da erva-mate no mercado gaúcho. A escolha do Rio Grande do Sul como mercado de interesse se deveu a sua impor- 
tância como produtor agrícola e, sobretudo, por ser o principal mercado consumidor de erva-mate do país. As séries de preços utilizadas descrevem o preço ao varejo e ao produtor agrícola, ambas em periodicidade mensal, do período janeiro de 1998 a dezembro de 2016. O preço ao varejo foi uma média de preços pagos pelos consumidores na cidade de Porto Alegre/RS, calculado pelo Centro de Estudos e Pesquisas Econômicas da Universidade Federal do Rio Grande do Sul (IEPE, 2017). O preço ao produtor refere-se ao preço médio da arroba de erva-mate em folha verde, computado pela Associação Rio-grandense de Empreendimentos de Assistência Técnica e Extensão Rural [Emater] (Ascar/RS) e disponibilizados pela Fundação de Economia e Estatística do Rio Grande do Sul [FEE] (2017). Ambas as séries de preços foram deflacionadas, com base em dezembro de 2016, de acordo com Índice Geral de Preços Disponibilidade Interna [IGP-D] da Fundação Getúlio Vargas e obtidos do site do Banco de Dados do Instituto de Pesquisa Economia e Aplicada (IPEADATA, 2017).

Para comparação do produto nos seus diferentes níveis de mercado foi necessário que o produto estivessemensurado em quantidade equivalente. Para a transformação do produto in natura - erva-mate em folha - no produto industrializado aplicou-se o fator de transformação de 3:1, isto é, 3,0 kg de erva-mate bruta para a elaboração de $1 \mathrm{~kg}$ de erva-mate para consumo, conforme Antoni (1999) e CERTI (2012). Tem-se assim, os preços entre os níveis de mercado representando uma unidade equivalente de produto.

Buscou-se também apresentar, um panorama geral do setor ervateiro brasileiro. Para tanto, apresentou-se informações referentes à produção, ao consumo e ao comércio externo nas últimas décadas.

\section{Resultados e Discussão}

Nesta seção apresentaram os dados da produção, consumo, e comércio externo da erva mate. Na parte da produção houve a divisão da produção extrativa e da produção plantada de erva-mate. Na sequência, foi descrita a relação entre área plantada e área colhida, essa diferença é importante por se tratar de uma cultura permanente e que leva longo período para que novas áreas entrem em efetiva produção. Informações sobre o consumo domiciliar e o comércio externo do produto seguiram para então entrar na análise da margem de comercialização, onde se investigou a evolução dos preços ao produtor e ao consumidor final, com objetivo de gerar um panorama geral da cadeia produtiva da erva-mate no Rio Grande do Sul.

\section{Produção}

Conforme ressaltado anteriormente, o sistema produtivo congrega a produção extrativa, advinda de ervais nativos, e a produção cultivada, proveniente de ervais plantados. A tabela 1 apresenta as informações concernentes à produção nacional de origem extrativa distribuída pelas unidades da federação no período 1990-2015.

Observa-se na tabela 1 que a produção total no início de 1990 girava em torno de 200 mil toneladas de erva-mate. Essa produção oscilou bastante nessa década, período de desregulamentação do setor e aumento da concorrência externa. A partir dos anos 2002 se tornou mais estável e passou a crescer nos anos finais, passando a um total de 330 mil toneladas de erva-mate em 2015. O valor bruto da produção teve comportamento similar, porém notou-se uma elevação, sobretudo nos três últimos anos, puxado pela melhoria dos preços. Cabe ressaltar que o produto extrativo, em geral é cultivado sombreado e apresenta sabor mais suave, utilizado em "blends" com a erva-mate proveniente de ervais cultivados (Valduga et al., 2003).

Outro ponto que se pode notar a partir da tabela 1 foi que o crescimento da produção nacional ocorreu com modificações regionais. Os estados de Santa Catarina e Rio Grande do Sul perderam espaço na produção extrativa, reduzindo a participação no total produzido de $33 \%$ e $29 \%$ em 1990 , para $8 \%$ e $5,5 \%$, em 2015 , respectivamente. Enquanto, o Paraná elevou sua produção e aumentou a participação no total produzido - $51 \mathrm{mil}$ toneladas ou 34\%, em 1990, para 292 mil toneladas ou $86 \%$ da produção em 2015. Assim, pode-se afirmar que a produção extrativa hoje está concentrada no Paraná.

A tabela 2 apresenta os dados referentes à produção cultivada de erva-mate. Nota-se que a produção foi crescente ao longo do período 1990-2015, multiplicando por quatro, de algo em torno de 150 mil toneladas em 1990 para cerca de 600 mil toneladas em 2015, porém o maior valor da produção ocorreu em 2001 (645 mil toneladas), reduzindo-se para lago em torno de 450 mil toneladas ao longo dos dez anos sequentes e retornando a crescer a partir de 2012. Em termos regionais houve elevação da produção em todos os estados. O Paraná experimentou um forte crescimento a partir de 1998, passando a ser o segundo maior produtor de erva-mate cultivada do país. Santa Catarina também experimentou crescimento, finalizando o período com quase 100 mil toneladas de produção. O Rio Grande do Sul, por sua vez, mesmo com o crescimento inferior aos demais estados, se manteve como o principal produtor de erva-mate cultivada do país por todo o período. Sua produção passou de $135 \mathrm{mil}$ toneladas em 1990 para 292 mil em 2015, ou seja, mais que dobrou nesses 25 anos e representou quase metade da produção nacional desse tipo de cultivo. 
Tabela 1. Quantidade produzida e valor bruto da produção de erva-mate extrativa no Brasil por unidade da federação, 1990-2015

\begin{tabular}{|c|c|c|c|c|c|c|c|c|c|c|}
\hline \multirow{2}{*}{ Ano } & \multicolumn{5}{|c|}{ Quantidade Produzida } & \multicolumn{5}{|c|}{ Valor Bruto da Produção } \\
\hline & $\mathrm{BR}$ & PR & $\mathrm{SC}$ & RS & MS & $\mathrm{BR}$ & PR & SC & RS & MS \\
\hline & & 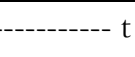 & & & ------ & & ------- & il reais -- & - & ------- \\
\hline 1990 & 150.823 & 51.695 & 49.959 & 44.404 & 4.765 & - & - & - & - & - \\
\hline 1991 & 209.327 & 49.229 & 109.724 & 45.735 & 4.639 & - & - & - & - & - \\
\hline 1992 & 208.298 & 48.524 & 111.665 & 44.727 & 3.382 & - & - & - & - & - \\
\hline 1993 & 243.690 & 64.016 & 121.203 & 54.835 & 3.636 & - & - & - & - & - \\
\hline 1994 & 207.980 & 61.875 & 75.857 & 67.402 & 2.845 & 89.922 & 27.191 & 29.879 & 32.534 & 317 \\
\hline 1995 & 204.065 & 59.022 & 79.350 & 63.412 & 2.281 & 113.667 & 34.279 & 41.294 & 36.827 & 1.266 \\
\hline 1996 & 169.031 & 77.052 & 53.468 & 36.369 & 2.142 & 100.155 & 51.564 & 27.589 & 20.020 & 982 \\
\hline 1997 & 189.469 & 100.640 & 53.525 & 32.822 & 2.482 & 86.128 & 40.697 & 25.780 & 18.531 & 1.120 \\
\hline 1998 & 183.504 & 104.811 & 51.403 & 25.622 & 1.667 & 84.279 & 43.952 & 25.398 & 14.069 & 860 \\
\hline 1999 & 176.922 & 106.978 & 45.057 & 23.095 & 1.791 & 86.015 & 46.932 & 24.626 & 13.613 & 844 \\
\hline 2000 & 174.481 & 109.575 & 39.967 & 23.234 & 1.706 & 92.509 & 52.134 & 24.289 & 15.085 & 1.000 \\
\hline 2001 & 182.177 & 122.695 & 33.506 & 24.001 & 1.975 & 109.179 & 65.624 & 25.156 & 17.108 & 1.291 \\
\hline 2002 & 229.701 & 109.798 & 71.642 & 44.974 & 3.288 & 225.523 & 62.655 & 151.826 & 10.752 & 290 \\
\hline 2003 & 220.189 & 105.867 & 68.393 & 43.646 & 2.283 & 63.547 & 37.636 & 15.996 & 9.642 & 274 \\
\hline 2004 & 246.837 & 137.809 & 66.078 & 42.350 & 600 & 76.362 & 49.985 & 16.122 & 10.192 & 63 \\
\hline 2005 & 238.869 & 139.657 & 61.635 & 37.173 & 404 & 76.712 & 50.002 & 16.411 & 10.249 & 50 \\
\hline 2006 & 233.360 & 152.971 & 41.833 & 38.127 & 429 & 86.934 & 61.890 & 12.110 & 12.883 & 50 \\
\hline 2007 & 225.957 & 156.444 & 40.559 & 28.603 & 352 & 87.667 & 63.731 & 14.264 & 9.630 & 41 \\
\hline 2008 & 219.773 & 154.701 & 39.637 & 25.156 & 279 & 102.635 & 78.459 & 14.806 & 9.337 & 34 \\
\hline 2009 & 218.102 & 156.563 & 36.493 & 24.764 & 282 & 86.587 & 62.977 & 13.380 & 10.191 & 39 \\
\hline 2010 & 227.462 & 166.682 & 36.274 & 24.231 & 275 & 100.526 & 75.611 & 14.996 & 9.884 & 35 \\
\hline 2011 & 229.681 & 169.549 & 36.117 & 23.579 & 436 & 118.049 & 91.854 & 15.184 & 10.925 & 87 \\
\hline 2012 & 252.700 & 193.636 & 36.105 & 22.720 & 239 & 155.294 & 127.468 & 15.611 & 12.163 & 52 \\
\hline 2013 & 300.128 & 254.915 & 25.217 & 19.813 & 183 & 322.216 & 275.421 & 26.753 & 19.998 & 44 \\
\hline 2014 & 333.017 & 287.334 & 25.291 & 20.205 & 188 & 403.121 & 363.539 & 20.193 & 19.322 & 67 \\
\hline 2015 & 338.801 & 292.891 & 27.074 & 18.655 & 181 & 396.282 & 354.197 & 24.918 & 17.080 & 86 \\
\hline
\end{tabular}

Fonte: IBGE (2017a)

O valor da produção apresentou trajetória similar à quantidade produzida na maior parte do período. $\mathrm{O}$ valor total da produção agrícola de erva-mate cultivada, na média do período 1994-2010 foi em torno a R\$ 100 milhões. No período mais recente, 2011-2015 houve um aumento do valor da produção mais do que proporcional ao aumento da quantidade produzida, assim o valor médio da produção gira em torno de $\mathrm{R} \$ 400$ milhões, influenciado pelo aumento de preços (Tabela 2).

Em relação à área colhida de erva-mate, descrita na primeira parte da tabela 3 , notou-se que a depois da desregulamentação, 1992, houve crescimento da mesma que passou de 20 mil hectares em 1995, para quase 95 mil hectares, em 2015. Notou-se que Rio Grande do Sul e Paraná apresentaram, na média dos últimos dez anos, 35 mil hectares de área colhida de erva-mate, Santa Catarina colheu 1/3. Em suma, parece que após a desregulamentação houve um aumento dos ervais plantados, que cresceram nos três estados sulistas, mas o Paraná além de manter a produção extrativa (Tabela 1) vem também crescendo a produção cultivada por meio de aumento de área reservada a esse cultivo. Os demais estados, aumentaram a área cultivada, substituindo o cultivo extrativo pelo cultivado.

O fato de a produção de erva-mate congregar a produção extrativa e plantada de uma cultura permanente, que demora um longo período para iniciar a produção, traz algumas particularidades para a compreensão de como os preços afetam a oferta primária desse produto. Assim, na segunda parte da tabela 3 apresenta-se a dife- 
rença percentual entre a área plantada e a área colhida de acordo com dados da Pesquisa Agrícola Municipal do Instituto Brasileiro de Geografia e Estatística [IBGE] (2017b). Assume-se que essa diferença deva ser creditada ao tempo em que um erval leva para entrar em produção. Isto é, como um erval plantado começa a produzir a partir do quarto ou quinto ano de seu plantio, a diferença entre a área plantada e área colhida mostra o quanto à área destinada a esse cultivo deve crescer quando da sua efetiva entrada em produção. Notou-se dos dados da tabela 3 que após a desregulamentação do setor, ano de 1992, cresceu essa diferença, girando em torno de 1/4 da área total plantada ao longo dos anos 1990, ou seja, houve um forte crescimento da área destinada à sua produção, que paulatinamente vai afetando a produção também crescente (Tabela 2). No período recente, de 20122015, houve uma redução dessa diferença para algo em torno de 8\%, ou seja, desaparecendo no Paraná e Santa Catarina, mas mantendo-se em algo como $16 \%$ no Rio Grande do Sul. Desta forma, parece que no Rio Grande do Sul houve, ainda no período mais recente, o contínuo aumento da área destinada ao cultivo de erva-mate, o que deve vir a afetar sua oferta nos próximos anos. Por fim, fica claro que pelo longo período de maturação desse tipo de investimento, o aumento dos preços leva algum tempo até levar ao aumento da oferta da erva-mate.

Tabela 2. Quantidade e valor da produção de erva mate proveniente de cultivos, por unidade da federação, 1990-2015

\begin{tabular}{|c|c|c|c|c|c|c|c|c|c|c|}
\hline \multirow{2}{*}{ Ano } & \multicolumn{5}{|c|}{ Quantidade Produzida } & \multicolumn{5}{|c|}{ Valor da Produção } \\
\hline & $\mathrm{BR}$ & PR & SC & RS & MS & $\mathrm{BR}$ & PR & SC & RS & MS \\
\hline & ----------- & - n & - n & - n & $\begin{array}{l}----- \\
---1\end{array}$ & ---------- & -------- & nil reais - & - n & $\begin{array}{ll}--- \\
---\end{array}$ \\
\hline 1990 & 147.072 & 6.106 & 4.996 & 135.970 & - & - & - & - & - & - \\
\hline 1991 & 166.431 & 5.628 & 34.624 & 126.179 & - & - & - & - & - & - \\
\hline 1992 & 145.973 & 6.222 & 16.516 & 123.230 & - & - & - & - & - & - \\
\hline 1993 & 227.338 & 8.308 & 23.102 & 195.917 & - & - & - & - & - & - \\
\hline 1994 & 222.377 & 17.246 & 27.930 & 177.181 & - & 37.984 & 2.057 & 5.077 & 30.839 & - \\
\hline 1995 & 247.214 & 20.277 & 39.371 & 187.546 & - & 49.299 & 2.728 & 6.909 & 39.638 & - \\
\hline 1996 & 214.576 & 34.677 & 51.615 & 128.284 & - & 38.648 & 4.408 & 9.501 & 24.738 & - \\
\hline 1997 & 307.327 & 43.725 & 46.017 & 212.632 & 4.953 & 54.188 & 5.518 & 8.371 & 39.880 & 419 \\
\hline 1998 & 424.433 & 167.509 & 53.932 & 197.361 & 5.631 & 70.539 & 22.732 & 7.645 & 39.703 & 459 \\
\hline 1999 & 462.665 & 167.509 & 71.312 & 218.183 & 5.661 & 83.397 & 28.644 & 10.045 & 44.306 & 402 \\
\hline 2000 & 522.019 & 206.188 & 63.203 & 244.477 & 8.151 & 91.810 & 31.959 & 9.524 & 49.860 & 467 \\
\hline 2001 & 645.965 & 339.139 & 48.834 & 252.045 & 5.947 & 131.634 & 66.457 & 8.466 & 56.326 & 385 \\
\hline 2002 & 513.526 & 221.779 & 45.600 & 240.252 & 5.895 & 119.334 & 50.038 & 6.899 & 61.845 & 551 \\
\hline 2003 & 501.702 & 201.694 & 52.474 & 238.949 & 8.585 & 100.936 & 42.669 & 7.671 & 49.752 & 844 \\
\hline 2004 & 403.281 & 133.449 & 37.577 & 222.884 & 9.371 & 118.156 & 29.621 & 5.792 & 81.793 & 948 \\
\hline 2005 & 429.730 & 164.752 & 37.629 & 218.982 & 8.367 & 107.130 & 40.372 & 5.644 & 60.229 & 885 \\
\hline 2006 & 434.483 & 165.076 & 35.292 & 229.569 & 4.546 & 132.402 & 45.109 & 5.840 & 80.956 & 496 \\
\hline 2007 & 438.474 & 136.266 & 37.909 & 259.317 & 4.982 & 143.613 & 37.699 & 8.090 & 97.268 & 556 \\
\hline 2008 & 434.727 & 132.556 & 41.890 & 256.352 & 3.929 & 148.592 & 40.406 & 11.253 & 96.482 & 450 \\
\hline 2009 & 443.126 & 135.000 & 46.254 & 258.651 & 3.221 & 156.385 & 43.124 & 11.888 & 100.960 & 413 \\
\hline 2010 & 430.305 & 123.132 & 43.266 & 260.413 & 3.494 & 160.778 & 40.258 & 10.688 & 109.383 & 447 \\
\hline 2011 & 443.635 & 122.202 & 45.614 & 272.719 & 3.100 & 173.589 & 44.776 & 11.377 & 117.022 & 415 \\
\hline 2012 & 513.256 & 180.853 & 69.064 & 260.866 & 2.473 & 234.199 & 91.182 & 24.842 & 117.830 & 345 \\
\hline 2013 & 515.451 & 195.403 & 50.740 & 265.515 & 3.793 & 406.518 & 154.440 & 32.545 & 217.611 & 1.921 \\
\hline 2014 & 602.559 & 225.078 & 98.594 & 276.232 & 2.655 & 670.201 & 284.366 & 82.120 & 302.935 & 779 \\
\hline 2015 & 602.899 & 217.851 & 91.349 & 292.386 & 1.313 & 579.191 & 248.523 & 69.885 & 260.233 & 550 \\
\hline
\end{tabular}

Fonte: IBGE (2017b) 
Tabela 3. Área colhida e diferença entre área plantada e colhida de erva mate proveniente de cultivos, por unidade da federação, $1990-$ 2015

\begin{tabular}{|c|c|c|c|c|c|c|c|c|c|c|}
\hline \multirow{2}{*}{ Ano } & \multicolumn{5}{|c|}{ Área Colhida } & \multicolumn{5}{|c|}{ Área não colhida } \\
\hline & $\mathrm{BR}$ & PR & SC & $\mathrm{RS}$ & MS & $\mathrm{BR}$ & PR & SC & $\mathrm{RS}$ & MS \\
\hline & - & -------- 1 & 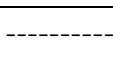 & ------ & ----- & - & -------- & $\%$ o ------ & (n- & - n \\
\hline 1990 & 8.494 & 881 & 293 & 7.320 & - & 0.2 & 0.0 & 0.0 & 0.3 & - \\
\hline 1991 & 10.211 & 885 & 1.462 & 7.864 & - & 0.1 & 0.8 & 0.5 & 0.0 & - \\
\hline 1992 & 10.844 & 1.200 & 757 & 8.885 & - & 19.4 & 0.0 & 4.7 & 22.5 & - \\
\hline 1993 & 18.841 & 1.138 & 1.132 & 16.568 & - & 15.7 & 43.1 & 1.4 & 13.7 & - \\
\hline 1994 & 16.457 & 2.713 & 1.349 & 12.390 & - & 39.8 & 29.2 & 11.5 & 43.7 & - \\
\hline 1995 & 22.754 & 2.907 & 2.311 & 17.531 & - & 33.9 & 34.0 & 18.8 & 35.5 & - \\
\hline 1996 & 32.836 & 4.712 & 10.636 & 17.488 & - & 25.6 & 19.1 & 0.0 & 36.8 & - \\
\hline 1997 & 39.379 & 5.610 & 9.448 & 23.948 & 373 & 25.8 & 13.7 & 10.5 & 31.5 & 63.3 \\
\hline 1998 & 57.429 & 23.507 & 10.000 & 23.542 & 380 & 19.9 & 0.0 & 7.4 & 35.2 & 62.8 \\
\hline 1999 & 62.154 & 23.507 & 12.035 & 26.205 & 407 & 18.9 & 0.0 & 4.5 & 33.6 & 63.3 \\
\hline 2000 & 69.029 & 28.944 & 11.104 & 28.384 & 597 & 15.6 & 0.0 & 13.8 & 26.8 & 50.0 \\
\hline 2001 & 84.029 & 42.658 & 10.453 & 30.525 & 393 & 13.3 & 0.0 & 19.7 & 23.8 & 66.6 \\
\hline 2002 & 79.616 & 39.260 & 8.872 & 31.063 & 421 & 17.0 & 0.0 & 21.4 & 30.8 & 0.0 \\
\hline 2003 & 84.438 & 43.038 & 10.293 & 30.519 & 588 & 20.8 & 14.4 & 21.0 & 28.5 & 7.3 \\
\hline 2004 & 74.800 & 37.023 & 9.751 & 27.397 & 629 & 12.6 & 17.3 & 22.2 & 0.7 & 3.8 \\
\hline 2005 & 76.101 & 38.654 & 9.674 & 27.185 & 588 & 23.0 & 13.8 & 21.2 & 33.4 & 33.3 \\
\hline 2006 & 78.633 & 39.092 & 9.760 & 29.448 & 333 & 13.8 & 0.0 & 16.6 & 26.0 & 44.7 \\
\hline 2007 & 74.526 & 33.573 & 10.213 & 30.375 & 365 & 17.1 & 12.5 & 10.0 & 23.3 & 30.1 \\
\hline 2008 & 71.217 & 31.695 & 9.243 & 29.993 & 286 & 18.1 & 11.9 & 22.1 & 22.6 & 32.5 \\
\hline 2009 & 70.588 & 31.976 & 8.083 & 30.292 & 237 & 15.6 & 10.0 & 25.5 & 17.9 & 33.6 \\
\hline 2010 & 68.183 & 30.447 & 8.231 & 29.257 & 248 & 4.5 & 0.0 & 17.8 & 4.6 & 0.0 \\
\hline 2011 & 71.185 & 31.773 & 8.406 & 30.786 & 220 & 0.2 & 0.0 & 0.0 & 0.2 & 31.0 \\
\hline 2012 & 76.347 & 36.688 & 10.753 & 28.731 & 175 & 8.0 & 0.9 & 0.0 & 17.9 & 0.0 \\
\hline 2013 & 67.397 & 29.643 & 9.397 & 28.105 & 252 & 9.4 & 0.7 & 0.2 & 19.5 & 0.0 \\
\hline 2014 & 70.835 & 28.309 & 13.460 & 28.772 & 294 & 8.8 & 1.1 & 0.2 & 18.4 & 0.0 \\
\hline 2015 & 94.945 & 51.826 & 12.912 & 29.978 & 229 & 3.8 & 1.0 & 0.2 & 9.5 & 27.1 \\
\hline
\end{tabular}

Fonte: IBGE (2017b)

\section{Comércio Externo}

A Tabela 4 apresenta os dados das exportações e importações brasileiras de erva-mate nos últimos 20 anos. Notou-se que a balança comercial do setor ervateiro sempre se mostrou superavitária, em torno de US\$ 27 milhões ano ${ }^{-1}$, no período 1997-2017. As importações se mostraram mais atraentes no período de taxa de câmbio valorizado, e, em alguns períodos como complementar da oferta interna. As importações brasileiras originaram sobretudo, da Argentina, fonte de mais de 95\% das importações brasileiras na média dos últimos cinco anos. Além disso, cabe destacar que cerca de 90\% dessas importações foram de erva-mate cancheada, produto de menor valor agregado e que complementou a oferta industrial interna. Outro ponto importante a ser levantado foi a existência de importações ilegais de erva-mate da Argentina, conforme Certi (2012), que é misturada à brasileira para venda no mercado nacional. Assim, haveria subestimação desse comércio nas estatísticas oficiais, sendo necessário maior fiscalização governamental e organização setorial para compreender/regular esse processo e quantificá-lo.

Pelo lado das exportações, o seu valor médio, nos vinte anos referidos, girou em torno de U\$ 30 milhões ano $^{-1}$ e 47 mil toneladas. As vendas ocorreram na forma de produto beneficiado. Em relação aos principais destinos, na média dos últimos cinco anos teve Uruguai (85\%), Chile (4,8\%), Estados Unidos (2,7\%) e Alemanha $(2,5 \%)$. Nota-se, portanto, que a erva-mate foi exportada sob a forma beneficiada e se direcionou, sobretudo ao Uruguai, país que possuí tradição similar aos estados sulistas brasileiras no que tange ao consumo de erva-ma- 
te, mas sem produção interna. Importa ressaltar que há uma ampla possibilidade de crescimento das exportações e diversificação de mercados, mas para tanto é necessá- rio intensificar o processo de investimento no desenvolvimento de novos produtos e na divulgação desses ao redor do mundo.

Tabela 4. Valor e quantidade total das exportações e importações de erva-mate para o Brasil, 1997-2017

\begin{tabular}{rrrrrrr}
\hline \multirow{2}{*}{ Ano } & \multicolumn{2}{c}{ Exportações } & \multicolumn{2}{c}{ Importações } & \multicolumn{2}{c}{ Saldo } \\
& Quantidade & \multicolumn{1}{c}{ Valor } & Quantidade & Valor & Quantidade & Valor \\
\hline 1997 & 25.190 & 34.608 & 18.535 & 8.874 & 6.655 & 25.734 \\
1998 & 25.433 & 34.077 & 14.839 & 6.170 & 10.594 & 27.908 \\
1999 & 25.409 & 30.174 & 9.775 & 3.135 & 15.634 & 27038 \\
2000 & 26.555 & 28.178 & 13.184 & 3.729 & 13.371 & 24.449 \\
2001 & 26.698 & 27.73 & 12.486 & 3.565 & 14.212 & 24.165 \\
2002 & 25.485 & 20.992 & 11.680 & 1.583 & 13.805 & 19.409 \\
2003 & 25.697 & 15.966 & 7.606 & 883 & 18.090 & 15.083 \\
2004 & 28.553 & 18.107 & 2.789 & 759 & 25.763 & 17.348 \\
2005 & 31.449 & 25.697 & 2.224 & 802 & 29.225 & 24.895 \\
2006 & 31.626 & 32.3 & 3.802 & 1.631 & 27.824 & 30.669 \\
2007 & 31.064 & 36.166 & 5.839 & 2.791 & 25.225 & 33.375 \\
2008 & 31.607 & 45.862 & 4.598 & 2.572 & 27.009 & 43.290 \\
2009 & 31.051 & 42.764 & 3.331 & 2.195 & 27.720 & 40.569 \\
2010 & 33.270 & 50.958 & 5.676 & 4.091 & 27.593 & 46.867 \\
2011 & 35.437 & 60.986 & 3.153 & 2.944 & 32.284 & 58.041 \\
2012 & 36.272 & 68.721 & 216 & 259 & 36.057 & 68.463 \\
2013 & 38.010 & 98.708 & 2.550 & 3.057 & 35.460 & 95.650 \\
2014 & 34.599 & 114.087 & 406 & 768 & 34.194 & 113.319 \\
2015 & 35.956 & 101.508 & $48 .-19$ & 101.354 \\
2016 & 35.325 & 82.355 & 135 & 214 & 35.190 & 82.141 \\
2017 & 13.181 & 29.787 & 115 & 148 & 13.067 & 29.639 \\
\hline
\end{tabular}

Nota: Códigos NCM 9030010; 9030090. Ano 2017 valores acumulados até maio/17

Fonte: MDIC (2017)

\section{Consumo}

Dados sobre o consumo de erva-mate são escassos. A fonte mais atualizada disponível se refere aos dados da Pesquisa de Orçamento Familiar [POF] do IBGE (2017c) realizada no ano de 2008. Para se obter informações desagregadas por unidade da federação recorreu-se aos microdados da pesquisa. A partir destes foi construída a tabela 5 que apresenta o consumo domiciliar per capita para os estados cujo consumo foi superior à média nacional.

Tabela 5. Consumo per capita de erva-mate no Brasil e principais unidades da federação, 2008

\begin{tabular}{cc}
\hline Unidade da Federação & $\begin{array}{c}\text { Consumo Per } \\
\text { Capita Erva Mate }\end{array}$ \\
\hline Rio Grande do Sul & ---- kg hab $^{-1}----$ \\
Paraná & 4,54 \\
Santa Catarina & 1,89 \\
Mato Grosso do Sul & 1,55 \\
Mato Grosso & 1,42 \\
BRASIL & 0,49 \\
\hline
\end{tabular}

Fonte: IBGE (2017c)
Observou-se que o Rio Grande do Sul tem o maior consumo anual per capita do país, com 4,5 kg por habitante, valor quase dez vezes superior à média nacional. $\mathrm{O}$ Paraná aparece em segundo lugar, com consumo anual per capita de 1,9 kg, seguido de Santa Catarina (1,55 kg) e Mato Grosso do Sul (1,45 kg). Esses foram também os estados onde a erva-mate foi produzida, indicando que houve uma relação entre produção e consumo da erva-mate. Esse consumo per capita foi condizente com o a participação desses estados no consumo total brasileiro que conforme Certi (2012) aponta o Rio Grande do Sul como principal mercado nacional (65\%), seguido do Paraná $(17 \%)$, de Santa Catarina $(12 \%)$ e do Mato Grosso do Sul $(2 \%)$. Cabe ressaltar que o consumo investigado pela POF, se restringiu ao consumo doméstico, não atingindo o consumo fora do domicílio. Algo que não deve alterar substancialmente as estimativas para o caso da erva-mate. De toda forma, o consumo anual per capita brasileiro foi bastante baixo $(0,5 \mathrm{~kg})$ se comparado vizinhos Argentina (5 kg) e Uruguai $(7 \mathrm{~kg}$ ) (Oliveira e Waquil, 2015). Nesse cenário, há grandes possibilidades ao setor ervateiro que poderia buscar alternativas de aumento do consumo doméstico. Estratégias de desenvol- 
vimento de novos produtos, de investimento em divulgação e marketing ressaltando os aspectos nutricionais, ecológicos e sociais dos produtos advindos da erva-mate poderiam ser alternativas a serem exploradas pelo setor para incrementar suas vendas.

\section{Preços}

A figura 1 apresentada a seguir, ilustra a evolução do preço da arroba de erva-mate recebida pelo produtor gaúcho. A evolução dos preços reais foi relativamente estável de janeiro de 1998 a janeiro de 2013. Quando os preços reais da arroba passaram de $\mathrm{R} \$ 13,02$ em maio de 2013 para $\mathrm{R} \$ 25,45$ em dezembro de 2013, ou seja, quase dobraram no período. Depois desse pico houve alguma oscilação, mas os preços foram retornando, paulatinamente, ao nível anterior ao choque de oferta da safra 2013.

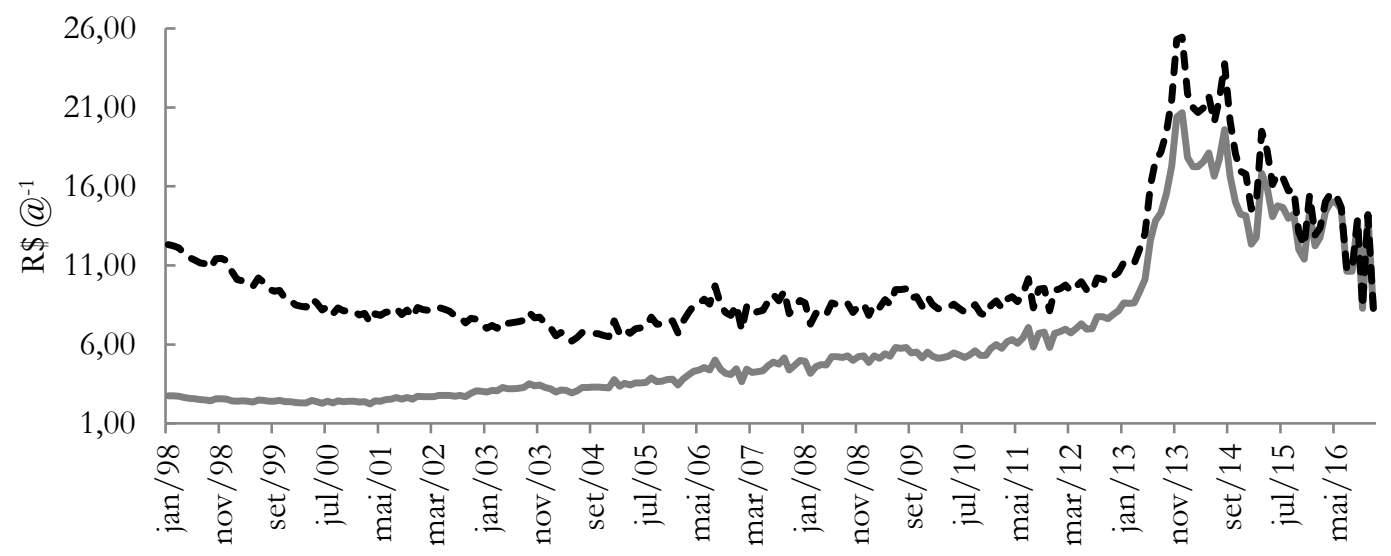

Preço Nominal ao Produtor - - - Preço real ao Produtor

Figura 1. Evolução dos preços da arroba de erva-mate, em termos nominal e real, recebido pelos produtores no Rio Grande do Sul, jan/1998 a dez/2016

Fonte: FEE (2017)

Os preços ao varejo apresentaram comportamento bastante similar aos preços recebidos pelos produtores, conforme se pode observar na figura 2 , até o início da safra de 2013. O preço nominal ao varejo em maio de $2013\left(\mathrm{R} \$ 10,15 \mathrm{~kg}^{-1}\right)$ se elevou e atingiu o pico em julho de $2014\left(\mathrm{R} \$ 16,11 \mathrm{~kg}^{-1}\right)$, variação de quase 60\%. Observou-se que o crescimento do preço ao varejo foi percentualmente menor, mas mais prolongado. Nos períodos seguintes este preço vem decaindo, mas ainda sem retornar ao nível anterior.

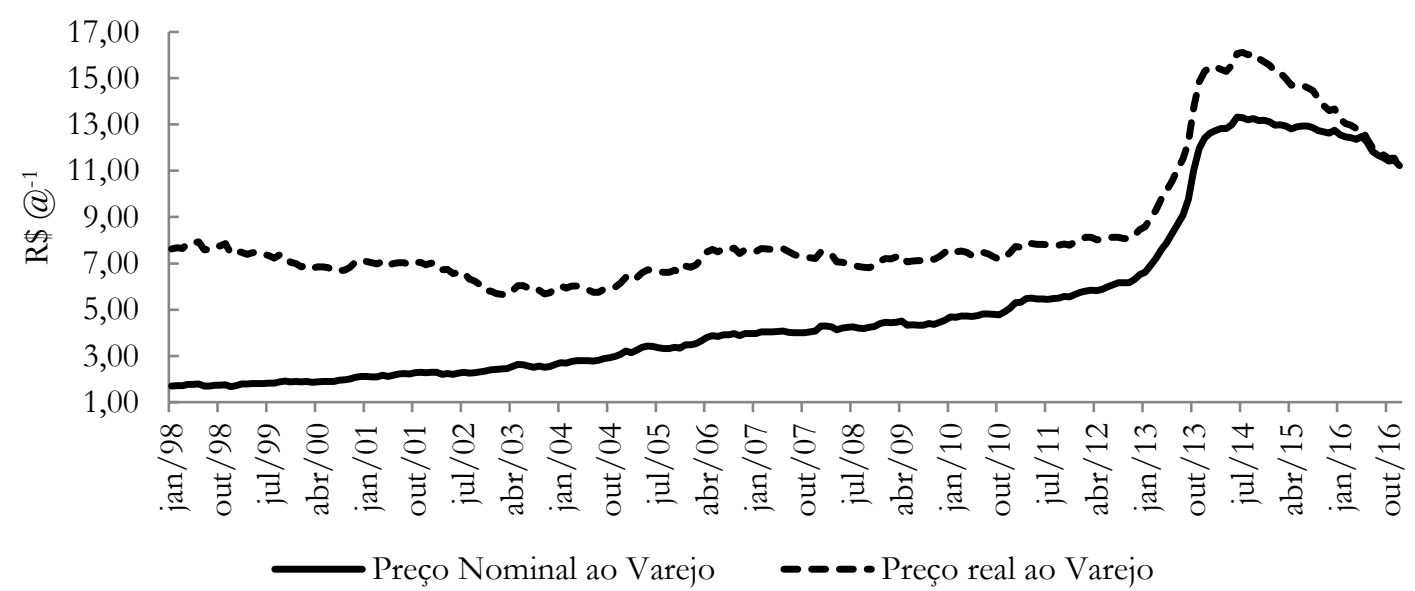

Figura 2. Evolução dos preços ao varejo da erva-mate (kg), em termos nominal e real, pagos pelos consumidores de Porto Alegre, RS, jan/1998 a dez/2016

Fonte: IEPE (2017) 


\section{Margens de Comercialização}

A figura 3 ilustra os principais conceitos de interesse desse trabalho. A margem de comercialização real absoluta (linha preta tracejada) e a margem de comercializa- ção relativa (linha vermelha vinculada ao eixo da direita). A margem absoluta, assim como os preços, apresentou um comportamento estável de janeiro de 1998 até meados de 2013.

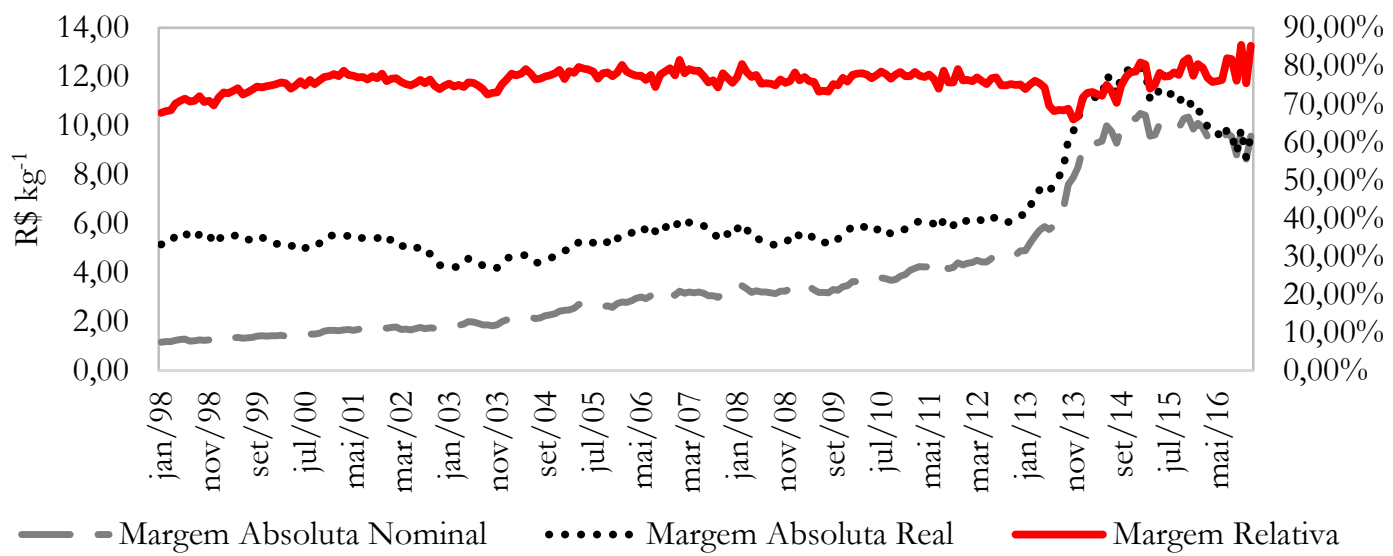

Figura 3. Evolução da margem de comercialização, absoluta nominal, absoluta real e relativa, da erva-mate no Rio Grande do Sul jan./1998 a dez./2016

Fonte: IEPE (2017) e FEE (2017)

A partir da safra de 2013 - de junho a setembro - a margem absoluta começa a se elevar mais rapidamente, atingindo seu pico em janeiro de $2015\left(\mathrm{R} \$ 12,37 \mathrm{~kg}^{-1}\right.$ equivalente). Seu crescimento acompanhou os preços ao varejo, e como estes não reduziram na mesma velocidade que preços ao produtor, parece que a margem está se estabilizando em um outro patamar, em torno de $\mathrm{R} \$ 9,00$ a $\mathrm{R} \$ 10,00$. Cabe ressaltar que essa margem absoluta congregou o pagamento de todos os serviços de comercialização que possibilitaram a entrega do produto in natura apto ao consumo final. Assim, teve-se nesta cifra a remuneração das atividades de intermediários, industriais e varejistas que disponibilizaram o produto final ao consumidor, em geral, nos supermercados e feiras das cidades.

Em relação a margem relativa, notou-se que esta também se encontrava em trajetória estável até a safra de 2013. Nesse momento houve uma queda dessa margem que passou de $74 \%$ em maior de 2013 para algo entre $65 \%$ a $66 \%$ entre novembro e dezembro de 2013. Nos períodos sequentes se recuperou e chegou a atingir mais de $85 \%$ no período final (dezembro de 2016).

Esses dados parecem refletir algum choque de oferta no setor primário em 2013. Havendo assim um aumento dos preços ao produtor mais que proporcional ao aumento dos preços ao varejo, o que fez com que a margem relativa recuasse, inicialmente, mesmo que com crescimento da margem absoluta. Por se tratar de um produto de consumo fortemente ligado a aspectos culturais, esperou-se uma demanda inelástica. A demanda não reduziu na mesma proporção que o aumento dos preços ao consumidor e estes preços responderam com defasagem e menos intensamente do que os preços ao produ- tor. Assim, a elevação das margens relativas decorreu de um preço ao varejo descendente, porém em velocidade menor que o preço ao produtor.

A tabela 6 apresenta as informações presentes nas figuras 1 a 3 em termos de comportamento médio anual para o período 1998-2016. Por se tratar de comportamento médio, atenua as variações presentes nas figuras, mas, de todo modo, percebeu forte crescimento nos preços a partir de 2013. O preço ao produtor em quantidade equivalente (preço ao produtor*) passou de uma média por $\mathrm{kg}$ de $\mathrm{R} \$ 1,97$ para $\mathrm{R} \$ 3,37$, elevação de 70,8\%. O preço ao varejo cresceu quase $40 \%\left(\mathrm{R} \$ 8,13 \mathrm{~kg}^{-1}\right.$ para $\mathrm{R} \$$ $\left.11,33 \mathrm{~kg}^{-1}\right)$ no comparativo 2012-2013. A margem absoluta elevou $29 \%\left(\mathrm{R} \$ 8,13 \mathrm{~kg}^{-1}\right.$ para $\left.\mathrm{R} \$ 11,33 \mathrm{~kg}^{-1}\right)$, e, somente a margem relativa apresentou um recuo $(-6,34 \%)$, passando de $76 \%$ para $71 \%$ de 2012 para 2013.

Em geral, em relação a margem relativa, observou-se que os agentes responsáveis pela intermediação - o beneficiamento industrial, a distribuição e a comercialização - responderam por algo entre $70 \%$ a $80 \%$ do valor final do produto comercializado. Este valor foi relativamente estável na maior parte do período anualizado - algo em torno de $74 \%$ a $78 \%$ - e indicou que os custos de transformação, transportes, distribuição e tributação absorveram uma parcela relativamente constante do valor final do produto. Esse equilíbrio se alterou com o choque de oferta no setor primário em 2013, que aumentou a participação do produtor para $29 \%$ do preço total (reduzindo a margem relativa para $71 \%$ ). Nos períodos posteriores a situação pareceu retornar ao equilíbrio prévio com a margem relativa passando para algo como 78\% em 2015, similar aos níveis anteriores. 
Tabela 6. Média anual dos preços reais recebidos pela erva-mate pelo produtor, pelo produtor em quantidade equivalente, pagos ao varejo, margem absoluta e margem relativa, 1998-2016, no Rio Grande do Sul

\begin{tabular}{|c|c|c|c|c|c|}
\hline Ano & $\begin{array}{l}\text { Preço ao } \\
\text { Produtor } \\
\end{array}$ & $\begin{array}{l}\text { Preço ao } \\
\text { Produtor }\end{array}$ & $\begin{array}{l}\text { Preço ao } \\
\text { Varejo } \\
\end{array}$ & $\begin{array}{l}\text { Margem } \\
\text { Absoluta }\end{array}$ & $\begin{array}{c}\text { Margem } \\
\text { Relativa } \\
\end{array}$ \\
\hline & ---- R\$@-1 ---- & & $\mathrm{R} \$ \mathrm{~kg}^{-1}$ & -------------- & ------- \% \\
\hline 1998 & 11.54 & 2.31 & 7.72 & 5.41 & 0.70 \\
\hline 1999 & 9.70 & 1.94 & 7.34 & 5.40 & 0.74 \\
\hline 2000 & 8.33 & 1.67 & 6.85 & 5.18 & 0.76 \\
\hline 2001 & 7.96 & 1.59 & 7.01 & 5.41 & 0.77 \\
\hline 2002 & 7.89 & 1.58 & 6.46 & 4.88 & 0.76 \\
\hline 2003 & 7.42 & 1.48 & 5.81 & 4.33 & 0.74 \\
\hline 2004 & 6.63 & 1.33 & 5.93 & 4.61 & 0.78 \\
\hline 2005 & 7.19 & 1.44 & 6.59 & 5.15 & 0.78 \\
\hline 2006 & 8.27 & 1.65 & 7.42 & 5.77 & 0.78 \\
\hline 2007 & 8.38 & 1.68 & 7.46 & 5.79 & 0.78 \\
\hline 2008 & 8.25 & 1.65 & 7.07 & 5.42 & 0.77 \\
\hline 2009 & 8.84 & 1.77 & 7.22 & 5.45 & 0.75 \\
\hline 2010 & 8.27 & 1.65 & 7.41 & 5.76 & 0.78 \\
\hline 2011 & 8.99 & 1.80 & 7.81 & 6.01 & 0.77 \\
\hline 2012 & 9.85 & 1.97 & 8.13 & 6.16 & 0.76 \\
\hline 2013 & 16.83 & 3.37 & 11.33 & 7.96 & 0.71 \\
\hline 2014 & 20.29 & 4.06 & 15.72 & 11.66 & 0.74 \\
\hline 2015 & 15.75 & 3.15 & 14.49 & 11.34 & 0.78 \\
\hline 2016 & 12.78 & 2.56 & 12.26 & 9.70 & 0.79 \\
\hline Total & 10.17 & 2.03 & 8.42 & 6.39 & 0.76 \\
\hline
\end{tabular}

Fonte: IEPE (2017) e FEE (2017)

As informações da tabela 6 corroboram a ideia de que o preço ao produtor cresceu mais que proporcionalmente o preço ao varejo. Assim, a margem relativa se reduziu, com a elevação da margem absoluta. $\mathrm{Na}$ sequência a menor velocidade de redução de preço ao varejo em relação ao preço primário fez com que a margem relativa crescesse. A inelasticidade da demanda pode ser a explicação desse comportamento.

Por fim, dois pontos mereceram destaque nesse cenário. Primeiro, por se tratar de uma cultura permanente, choques de oferta tendem a levar mais tempo para se estabilizarem, pois a oferta demora a responder ao incentivo dado pelos preços. A possibilidade de importações se mostrou benéfica aos industriais/varejistas e aos consumidores, mas restringiram os ganhos dos produtores. $\mathrm{O}$ segundo ponto foi que as informações de preços, tanto ao produtor quanto a consumidor, no mercado gaúcho sinalizaram algum choque de oferta no período da safra 2013. Porém, os dados da produção do IBGE $(2017$ a,b) não evidenciaram esse fato, enquanto a produção gaúcha cultivada passou de 260 mil toneladas em 2012 para 265 mil toneladas em 2013, a produção extrativa, recuou de 22,7 mil toneladas para 19,8 mil toneladas nesse mesmo período (Tabela 1 e 2). A hipótese de queda da produção ganhou espaço também pelo aumento das importações passando de 200 toneladas em 2012 para 2,5 mil toneladas em 2013 (Tabela 4). Notícias vinculadas à imprensa na época reforçaram a hipótese que a valorização do preço da erva mate em 2013 foi causada por uma quebra de safra decorrente de problemas climáticos no ano anterior. Mais especificamente, o clima seco seguido de geada foi o fator responsável pela redução a produtividade. A redução da informalidade foi apontada como o caminho para a evolução do setor, que carece de dados disponíveis no que se refere à efetiva quantidade de hectares da erva no Rio Grande do Sul ${ }^{1}$. Ainda, nesse sentido, a Fundação Certi (CERTI, 2012) apontou que os registros e estatísticas relacionados à produção e comercialização da erva-mate foram dispersos e conflitantes. Assim, parece que a construção, sistematização e divulgação de informações de estatísticas mais apuradas é imprescindível para o desenvolvimento do setor.

Em suma, o trabalho teve por objetivo investigar a evolução da margem de comercialização da erva-mate no mercado gaúcho no período janeiro 1998 a dezembro de 2016. Os resultados indicam que a margem, tanto absoluta quanto relativa, apresenta um comportamento estável na maior parte do período (1998-2012). Mas u

${ }^{1}$ Canal Rural. 2013. Produtores comemoram valorização do preço da erva-mate no Rio Grande do Sul. Disponível em: $<$ http://www.canalrural.com.br/ noticias/agricultura/produtores-comemoram-valorizacao-preco-erva-mate-rio-grande-sul-25489>. Acesso em 25 jun. 2017. 
choque de oferta, na safra de 2013, alterou esse cenário, reduzindo inicialmente a margem relativa e elevando a margem absoluta; com o passar do tempo essa relação se inverte, e a margem absoluta decai enquanto a relativa cresce. Isto pois, inicialmente, as variações no preço ao varejo são menores proporcionalmente em relação às variações no preço ao produtor. O cenário de retorno ao nível anterior da margem ainda não está claro, apesar da redução efetiva e dependerá do comportamento da demanda e, sobretudo, da oferta, do produto nos próximos anos, dado longo tempo para um erval entrar em produção. Outros aspectos importantes são: o aumento da produção cultivada, iniciada pela desregulamentação do setor e a abertura comercial proveniente do Mercosul; a erva-mate se mostra como um produto de consumo interno, mas com um saldo comercial positivo advindo das vendas, sobretudo, ao Uruguai; o consumo bastante regionalizado, com destaque para: Mato Grosso do Sul, Paraná, Santa Catarina e, especialmente, para o Rio Grande do Sul.

\section{Conclusão}

Os resultados do trabalho indicaram a importância que choques de oferta tiveram sobre a margem de comercialização. Dentre os desafios para o setor ervateiro, destaca-se a importância de se elevar o consumo, em especial, no mercado interno. Entende-se que explorar o contexto de alterações dos hábitos alimentares com a diversificação de produtos que ressaltem atributos (nutricionais, ecológicos, culturais e sociais) pode ser uma saída para o aumento do consumo do mate com grandes potencialidades para o setor.

Por se tratar de uma cultura permanente, a decisão de plantio por parte do produtor depende da expectativa de rentabilidade no longo prazo. Neste caso, a existência de informações fidedignas sobre o setor nas suas diferentes esferas - produção, área plantada, área nativa, consumo, empregos, volume beneficiado, tipos de produtos vendidos, etc - reveste-se de grande interesse a todos agentes vinculados ao setor ervateiro e se mostra como outro importante desafio a ser superado.

Por fim, importa ressaltar o componente regional deste setor. Trata-se de um produto cujo hábito de consumo está na tradição de parcelas importantes da população brasileira, sobretudo na região Sul, e sua dinamização pode ter impactos consideráveis nas economias locais vinculadas a ele.

\section{Referências}

Antoni, V.L. 1999. A estrutura competitiva da indústria ervateira do Rio Grande do Sul. Teoria e Evidência Econômica 7(12): 49-68. Disponível em: <http://cepeac.upf.br/ download/rev_n12_1999_art3.pdf>. Acesso em: 21 jun. 2017.
Barros, G.S.deC. 2007. Economia da Comercialização Agrícola. Disponível em: <https://edisciplinas.usp.br/pluginfile. php/3041978/mod_resource/content/3/BARROS_COMERCIO.PDF>. Acesso em: 21 jun. 2017

Empresa Brasileira De Pesquisas Agropecuárias [EMBRAPA]. 2010. Cultivo da Erva-Mate: Importância socioeconômica e ambiental. Disponível em: <https://www.spo.cnptia. embrapa.br/temas-publicados $>$. Acesso em: 20 jun. 2017.

Food and Agriculture Organization of the United Nations [FAO]. 2017. Faostat. Disponível em: < http://www.fao.org/ faostat/en/\#data/QC>. Acesso em: 24 jun. 2017.

Fundação Centros de Referência em Tecnologias Inovadoras [CERTI]. 2012. Análise Integradas das Cadeias Produtivas nativas da FOM e seus impacto sobre este Ecossistema. Volume I - Relatório Final: Diagnósticos das Cadeias Produtivas do Pinhão e da Erva Mate. Disponível em: <http://www.fundacaogrupoboticario.org.br/_layouts/ FundacaoWebpartLibrary $/$ Download.aspx? file $=$ L3B0L0FyYXVjYXJpYUFuZXhvL1ZvbHVtZSBJIC0gRGlhZ25vc3RpY28gZGFzIGNhZGVpYXMgcHJvZHV0aXZhcyBkbyBwaW5oYW8gZSBkYSBlcnZhIG1hdGUucGRm>. Acesso em: 20 jun. 2017.

Fundação de Economia e Estatística Siegfried Emanuel Heuser [FEE]. 2017. Preços recebidos pelos produtores - EMATER. Disponível em: <http://feedados.fee.tche.br/feedados/>. Acesso em: 10 jun. 2017.

Instituto Brasileiro de Geografia e Estatística [IBGE]. 2017a. Produção da Extração Vegetal e Silvicultura - SIDRA/ PESV. Disponível em: <https://sidra.ibge.gov.br/tabela/289>. Acesso em: 20 jun. 2017.

Instituto Brasileiro de Geografia e Estatística [IBGE]. 2017b. Pesquisa Agrícola Municipal - SIDRA/PAM. Disponível em: <https://sidra.ibge.gov.br/tabela/1613>. Acesso em: 20 jun. 2017.

Instituto Brasileiro de Geografia e Estatística [IBGE]. 2017c. Pesquisa de Orçamentos Familiares - POF. Disponível em: <http://www.ibge.gov.br/home/estatistica/populacao/ condicaodevida/pof/2008_2009/microdados.shtm>. Acesso em: 20 jun. 2017.

Instituto de Estudos e Pesquisas Econômicas [IEPE]. 2017. Banco de Dados. Disponível em: < http://www.ufrgs.br/iepebanco/>. Acesso em: 24 jun. 2017.

Instituto de Pesquisa Econômica e Aplicada (Banco de Dados) [IPEADATA]. 2017. Disponível em: <http://www.ipeadata. gov.br/>. Acesso em: 24 jun. 2017.

Ministério do Desenvolvimento, Indústria e Comércio Exterior [MDIC]. 2017. Secretaria de Comércio Exterior (SECEX). ALICEWEB. Disponível em: < http://aliceweb.desenvolvimento.gov.br/>. Acesso em: 18 jun. 2017.

Oliveira, D.S.V., Waquil, P.D. 2015. Dinâmica de produção e comercialização da erva-mate no Rio Grande do Sul, Brasil. Ciência Rural, Santa Maria, online. 45, 4, 750-756. Disponível em: <http://dx.doi.org/10.1590/0103-8478cr20140276>. Acesso em: 20 jun. 2017.

Rio Grande do Sul. 2003. Lei n. 11.929, de 20 de junho de 2003. Institui o churrasco como "prato típico" e o chimarrão como "bebida símbolo" do Estado do Rio Grande do Sul e dá outras providências. Disponível em: <http://www. al.rs.gov.br/filerepository/repLegis/arquivos/11.929.pdf>. 
Acesso em: 24 jun. 2017.

Valduga, A.T.; Finzer, J.R.D.; Mosele, S.H. 2003. Processamen-

to de Erva-Mate. EdiFAPES, Erechim, RS, Brasil. 